\title{
O MODERNO NA ARQUITETURA DA PAISAGEM E A OBRA DE WALDEMAR CORDEIRO
}

\section{MARCOS CASTILHA}

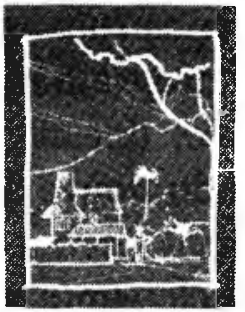

O texto subseqüente se constitui em uma síntese de alguns aspectos contidos no relatório final de bolsa de iniciação científica, intitulado "A arquitetura Paisagística e a Cidade, do Ecletismo ao Moderno: fundamentos conceituais e rebatimentos espaciais", trabalho este desenvolvido no período de 1988 a 1990 . O referido relatório aborda a evolução urbana e a arquitetura da paisagem, praticada na cidade de São Paulo, no período de 1920 até fim da década de 60.

Como tema central deste texto síntese, optamos por um panorama sintético da produção do artista plástico e paisagista Waldemar Cordeiro, produção esta de grande riqueza e que merece maior divulgação.

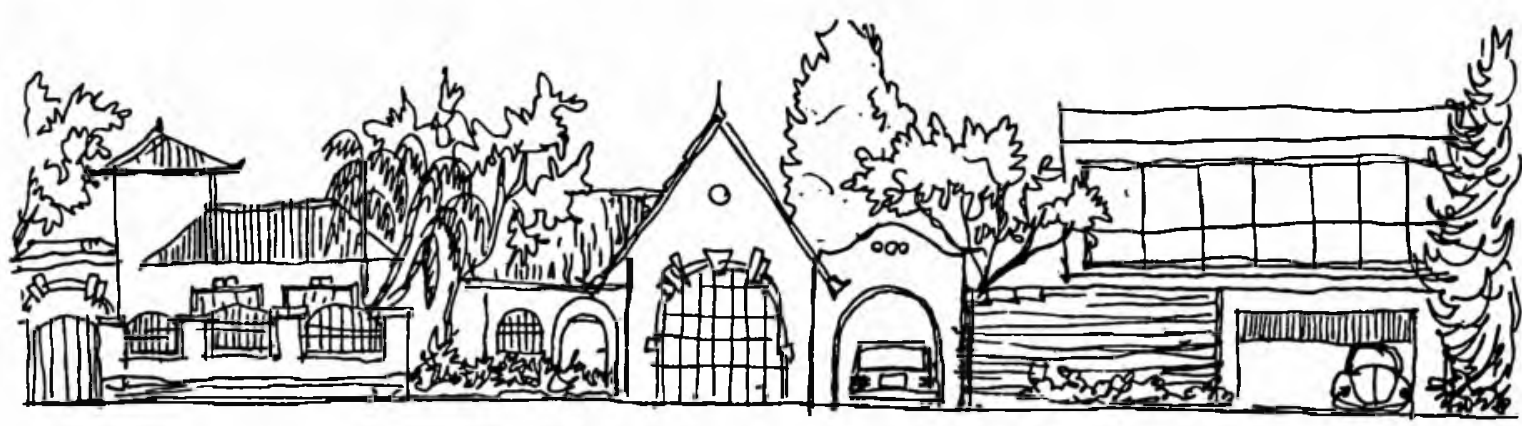

a) - Residências

As alterações verificadas durante o período da São Paulo, "Cidade do Café", instituíram o espaço livre na residência. Com recuos em todos os limites do lote, nas residências maiores ou, pelo menos, o recuo frontal e de fundos, na versão mais simples. Em todas as tipologias, tornou-se inerente a presença da área verde, "jardim", por menor que fosse.

$\mathrm{Na}$ transição e afirmação do moderno, o jardim já tido como um elemento essencial, ganhou progressivamente novas formas de abordagem. No entanto, com a mesma força com que permaneceu quase imutável o sistema estrutural urbano, baseado no lote, quase sempre retangular, também perdurou durante 
muito tempo um sistema de implantação, dotado de recuos, mas totalmente tradicional. Mesmo com as modificações a nível de arquitetura, passando pelo neocolonial e englobando o moderno, teríamos muito forte a forma de implantação com a residência alinhada com os eixos do lote, independente das dimensões grandes ou pequenas deste.

Esta distribuição dos espaços externos correspondia à uma situação típica de planta e programas internos. Todas as novas introduções na arquitetura ficavam restritas à decoração interna e externa ou algumas soluções construtivas diferentes. Porém, quando relativas às novas implantações ou programas, eram barrados pelo conservadorismo paulistano. Por este motivo, durante este período transitório vigente até o pós-guerra, a partir de quando houve a explosão real dos preceitos modernos, os programas das residências permaneciam muito presos a padrões ainda da São Paulo do Café e do ecletismo: a mesma hierarquia de espaços, as peças de distribuição interna, o jardim monumental à frente, o "vergonhoso" quintal aos fundos. Isto se mantinha quase que imutável sob um leque de "casas" neocoloniais, chalés, art-déco e até "modernistas" 1.

O tratamento dos jardins, traduzido a nível de piso, organização de circulação, plantação e equipamentos, durante estes tempos de transição, passou por um processo de falta de identidade. Os conceitos e regras no traçado dos jardins de estilo, com plantas pitorescas e podas complexas, começaram a se inviabilizar por dificuldades de manutenção ou exigüidade de terreno.

Mas na seqüência não surgiu uma "nova corrente", com uma nova ideologia e novas "regras", mostrando como deve ser um jardim belo. Isto só viria a ocorrer quando da afirmação definitiva da arquitetura moderna, ampliando o campo para os paisagistas modernos, a citar de início Roberto Burle Marx.

A "acefalia" citada traduziu-se por um grande número de jardins sem premissas ou ideologias evidentes. Havia uma mistura de elementos, novos e antigos, empregados de muitas formas, mas sem uma intenção arrojada. Muitas vezes havia o descambo para o aleatório.

As plantas exóticas, neste período, já haviam perdido um bom espaço para a vegetação nativa. Talvez pela popularização do trabalho de Burle Marx, cujos primeiros jardins datam já da década de 30 . De qualquer modo, as folhagens tropicais, quando consideradas bonitas, viriam bem a calhar pela sua facilidade de manutenção, em detrimento da poda topiária.

Mas a vegetação tropical ainda não despontou com uma abordagem plástica moderna. Ainda seriam inseridas em concepções tradicionalistas de jardim. 


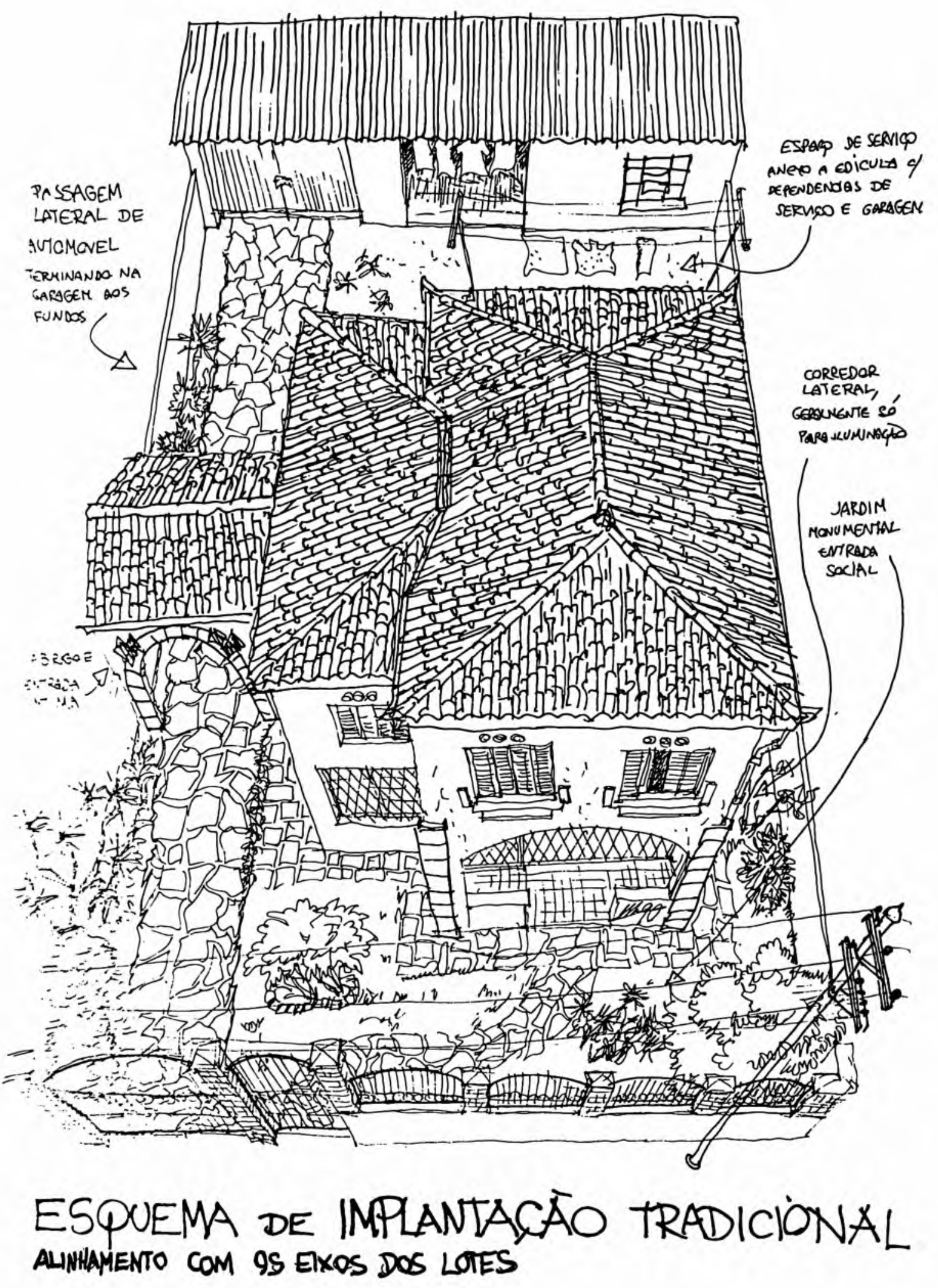

b) - Residência implantada tradicionalmente 
No entanto, conseguiríamos divisar, durante este período, alguns exemplares cujos espaços configurariam agradáveis. $\mathrm{O}$ bom resultado especial seria obtido não pela atenção a correntes e teorias, mas pelo emprego da intuição do próprio paisagista ou "jardineiro".

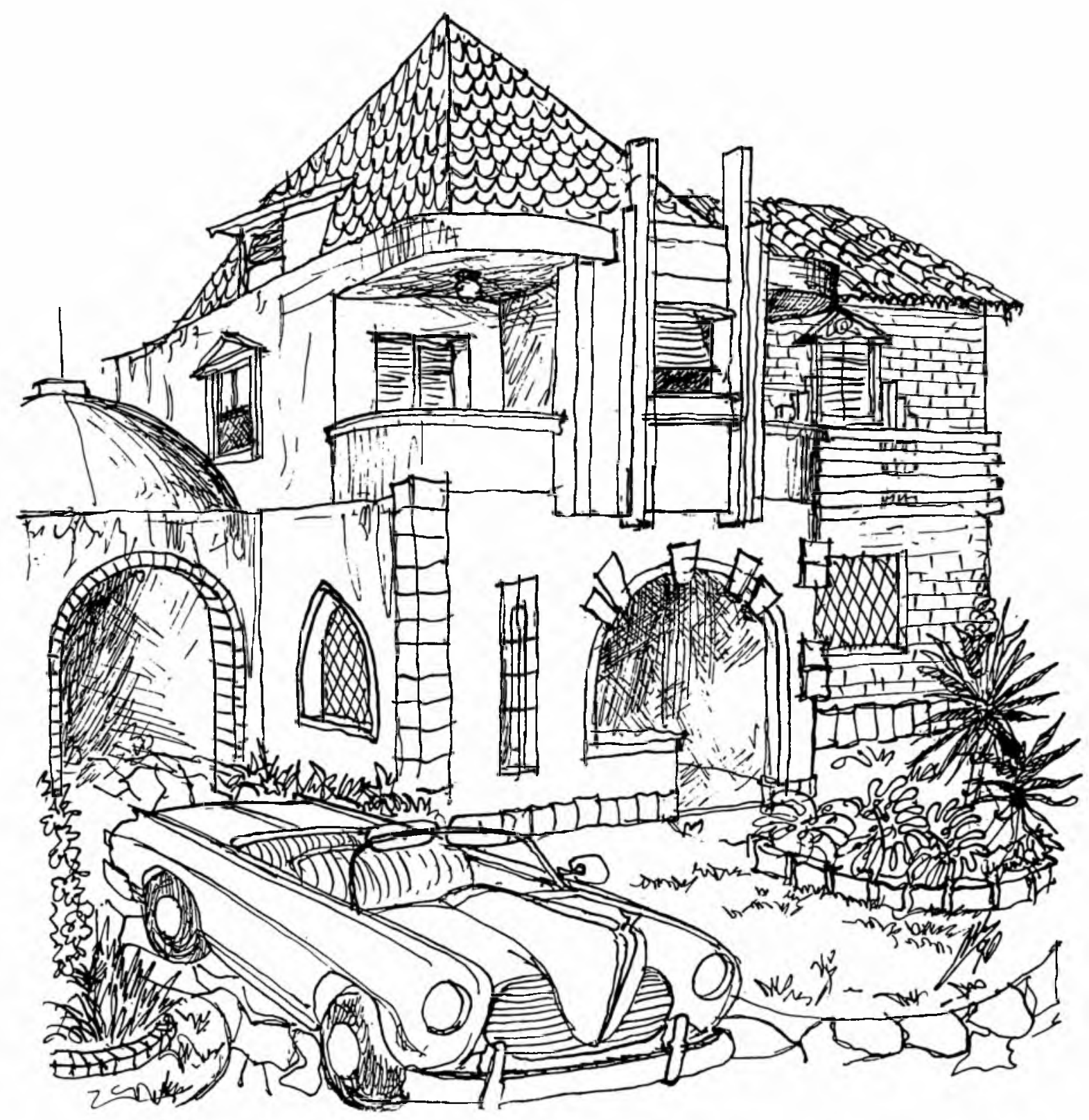

c) Ilustração - Salada Estilística 
O termo "jardineiro" é bem propício, pois poderíamos notar na concepção destes jardins, o emprego de conceitos mais próximos do intuitivo, mais ligados a tradições rurais do que conceitos ligados a uma análise urbanística ou então análises socioculturais da paisagem.

Mas a modernidade não tardaria a se efetivar: a evolução econômica, a evolução tecnológica, influências externas. Todo um leque de fatores contribuiu para que cada vez mais se afirmasse uma nova maneira de se conceber a arte, a arquitetura e também a arquitetura da paisagem.

O pós-guerra, particularmente a década de 50 , caracterizou-se pela afirmação da arquitetura moderna. É uma década que já assumiu um "perfil" bem definido e com poucos remanescentes dos academicismos.

Nomes que muito anteriormente já haviam se manifestado: Artigas, Niemeyer, Levi, etc. seriam agora efetivamente os mestres.

Afirmou-se uma corrente moderna também no paisagismo, que poderíamos, sem ressalva, atribuir em grande parte ao pioneiro Roberto Burle Marx. Uma corrente que, no âmbito geral, fez a união entre os aspectos ecológicos nacionais e relativos ao espírito e à natureza, com uma visão urbanística e sociocultural. A importância do jardim e da paisagem em seu caráter cultural e na qualificação da vida urbana.

No âmbito interno ao lote, a residência propriamente dita, conceitos como o pátio interno, ou integração espaço interno e externo, foram levados às últimas conseqüências. Primeiramente, isto se fez possivel com uma grande renovação nos programas das residências e também na aceitação de novas formas de implantação. Uma grande alteração foi a incorporação definitiva da garagem próxima à rua, sem a passagem lateral. Acreditamos que isto se consolidou também pela popularização do automóvel, trazendo a necessidade de abrigos mais largos para a acomodação de maior número destes. Mais inovador ainda seria a localização de áreas de serviço na parte frontal, como volumes cegos, de grande força formal. Estes liberaram grandes áreas internas para espaço de lazer.

Houve uma grande quebra com a antiga hierarquia de desvalorização das áreas de serviço. Quebra tão evidente também, pela eliminação de "compartimentos" e integração de áreas como cozinhas e sala de jantar e estar. Integração é a palavra de ordem².

O jardim, de modo geral, passou a buscar uma relação de intimidade e de uso afetivo com o usuário. Uso de lazer, de estar, de retiro, mas tudo isto sob um 
caráter mais intenso e próximo. Áreas de pequenas dimensões seriam tratadas de modo a resultarem em espaços intensos. Também os jardins frontais perderam o caráter "emoldurador" da residência, embora muitos dos arquitetos e paisagístas passassem a concebê-los totalmente abertos para a rua. Estes últimos passariam a ter uma preocupação com o ambiente da rua e calçada, o todo maior onde a casa se insere. $\mathrm{O}$ realce à edificação se faria por um caráter "convidativo" e não "monumental".

No tratamento específico dos jardins, particularmente em São Paulo, seriam eleitas definitivamente as folhagens densas e as parasitas: "Monsteras", "Philodendron", "Marantas" "Helicôneas", "Embaúbas". Os jardins das décadas de 50 e 60 seriam marcantes pela densa plantação destas espécies.

Roberto Burle Marx, quando da afirmação do movimento moderno, obteve com sua produção paisagística uma repercussão equivalente a do trabalho de Oscar Niemeyer. Ambos foram, e são, aclamados como expoentes oficiais da arquitetura moderna brasileira.

O trabalho de Burle Marx obviamente repercutiu e influenciou a produção paisagística moderna paulistana, mas não a ponto desta assumir um "rosto Burlemarxiano", como no Rio de Janeiro. Isto talvez devido às características climáticas, sociais ou até "metafísicas" da cidade de São Paulo, muito diversas das do Rio de Janeiro, onde Burle Marx fez germinar sua filosofia e estilo, vinculados à exuberância da paisagem. A feição do paisagismo moderno paulistano seria moldada por dois outros expoentes: Roberto Coelho Cardozo e Waldemar Cordeiro. O nome de Roberto Coelho Cardozo é mais popular no meio especializado da arquitetura. Iniciou seu trabalho no Brasil por volta da década de 50 , período em que chegou ao Brasil vindo de uma longa estadia nos Estados Unidos, onde teve sua formação acadêmica.

A leitura do embasamento teórico de Roberto Cardozo feita aos nossos dias, pode parecer um tanto "sem novidades". Isto acontece porque os preceitos modernistas hoje são inerentes à maneira de projetar. Mas se contrapostos ao pano de fundo da São Paulo recém-saída do ecletismo, na década de 50, vemos quanto avanço eles representaram.

Falando ainda especificamente dos pressupostos sobre paisagismo, estes podem parecer ainda mais conhecidos ou incorporados. E nada seria mais normal, já que Cardozo foi formador de uma geração paulista de paisagistas, que por sua vez já ensinaram outra geração. Os pressupostos de Cardozo, e por tabela, de Garret Eckbo, foram em grande parte incorporados no ensino do paisagismo $^{3}$ 


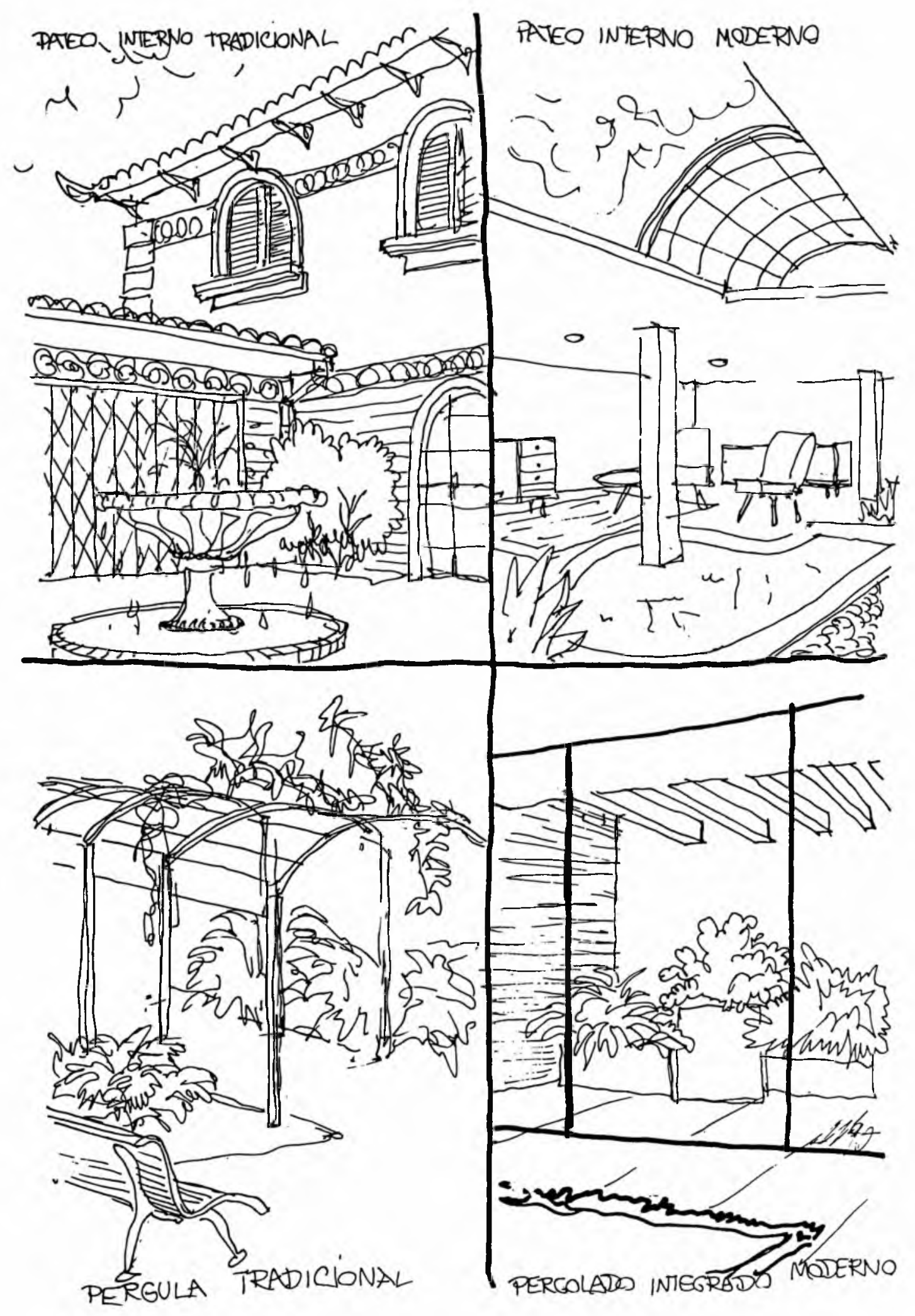

d) - Pergula, pátio interno 
Quando observamos a origem da obra de Roberto Cardozo, vemos que ela tem raízes na obra de Garret Eckbo nos Estados Unidos. Cardozo foi em grande parte um defensor das idéias de Eckbo, empregando-as nas condições tupiniquins. Tivemos neste aspecto uma das principais diferenças, e também a principal característica da obra de Waldemar Cordeiro. Este foi o criador de uma outra linha de Paisagismo, autor que criou desde a conceituação e ideologia até as linhas de projeto. Sua corrente foi absolutamente original, não tendo os traçados ou soluções inspirados em outros traçados e soluções. Os projetos são fruto puramente de construção sobre um embasamento conceitual.

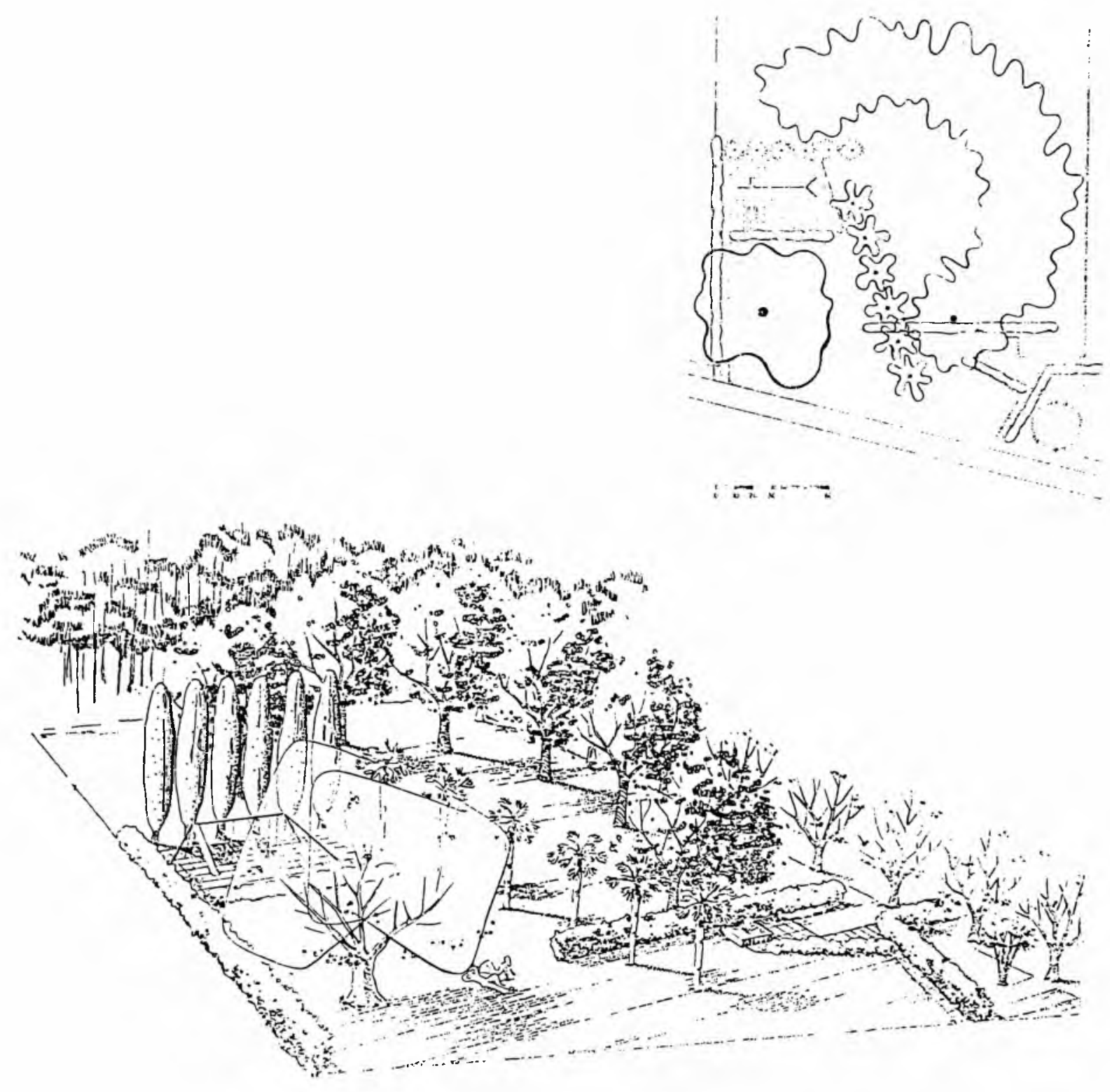

e) - Projeto Garret Eckbo Projeto Paisagístico de Garret Eckbo. (Fonte: Landscape for Living.) 
Waldemar Cordeiro chegou ao Brasil em 1946, tendo realizado estudos artísticos na Academia de Belas Artes de Roma, conhecedor de história da pintura e com desembaraço necessário para realizar aqui, lá pelos idos de 1947, a pintura da Capela de Santa Rita na Igreja do Bom Jesus, no Bráz. Era já crítico o suficiente para publicar caricaturas em jornais editados em língua italiana.

Em 1948 está radicado definitivamente no Brasil. E nesta época, já iniciava suas pesquisas em função do abandono da arte como "expressão" e da busca de uma arte "contingente", Cordeiro iniciou sua defesa ferrenha ao abstracionismo nas artes plásticas.

Nos idos de 1949, Cordeiro e um grupo de artistas de São Paulo, como Sacilotto, Geraldo de Barros, Kasmer Fejer, Maurício Nogueira Lima e Lothar Charoux, já pesquisavam conceitos em função da arte concebida racionalmente: a obra como projeto.

O início da década de 50 marcou o primeiro contato de Cordeiro com o paisagismo. Embora sendo descendente de gerações de seringalistas e filho de agrônomo, Cordeiro se iniciou nesta atividade por sugestão de Villanova Artigas. $\mathrm{O}$ trabalho mais antigo que se conhece de Cordeiro corresponde a um projeto em parceria com Artigas.

A partir daí realizou cerca de 200 projetos até o seu falecimento em 1973.

Paralelo a esta atividade, prosseguiram suas atividades de artista plástico e crítico, sendo o principal "cabeça" de manifestos como o "Ruptura" de 52, que reuniu artistas abstratos e concretos, também participou e promoveu exposiçōes como a 1aㅡ Exposição Nacional de Arte Concreta.

Suas últimas pesquisas foram em torno da Arte por computador, um pioneirismo, desenvolvido no equipamento da Unicamp. O Circuito Eletrônico seria uma forma de se ultrapassar o limite do circuito das galerias de arte, bem como as distâncias urbanas e descontinuidades espaciais da cidade ${ }^{4}$

Cordeiro foi líder e teórico do movimento concretista nas artes plásticas em São Paulo. Talvez não fosse exagero afirmar que as artes plásticas, no sentido tradicional da palavra, fossem sua verdadeira paixão. $O$ paisagismo surgiu na vida de Waldemar Cordeiro inicialmente como um meio de subsistência, uma forma de sustentar o artista plástico. Polêmico e sempre na posição de vanguarda, preocupava-se intensamente com o conceito, a coerência e o papel de seus trabalhos. Devido a isto não chegou a produzir tanto sob o ponto de vista 
quantitativo. "Ele germinava as idéias lentamente e por falta de tempo acabava fazendo poucas obras.. ${ }^{5}$

O conceito popular da obra de arte gira em torno de algo que "representa" ou "registra" um momento, uma idéia ou situação. Algo cercado de conceitos subjetivos como "sentir", "exprimir sensibilidade", etc. Também, este conceito muitas vezes atribui à obra de arte um valor decorativo. A busca, na produção de Cordeiro sempre foi antagônica a isto, pois ele buscava a arte como uma "coisa" interativa e participante na vida, comunicação e sociedade. Alguns poderiam dizer que esta seria uma comparação grosseira, mas poder-se-ia dizer que, nas aspirações de Cordeiro, a obra de arte assumiria um papel "fundamental", semelhante a um pilar de concreto, estrutural, abandonando a posição de somente algo bonito, sobreposto e de certo modo até bem dispensável da vida.

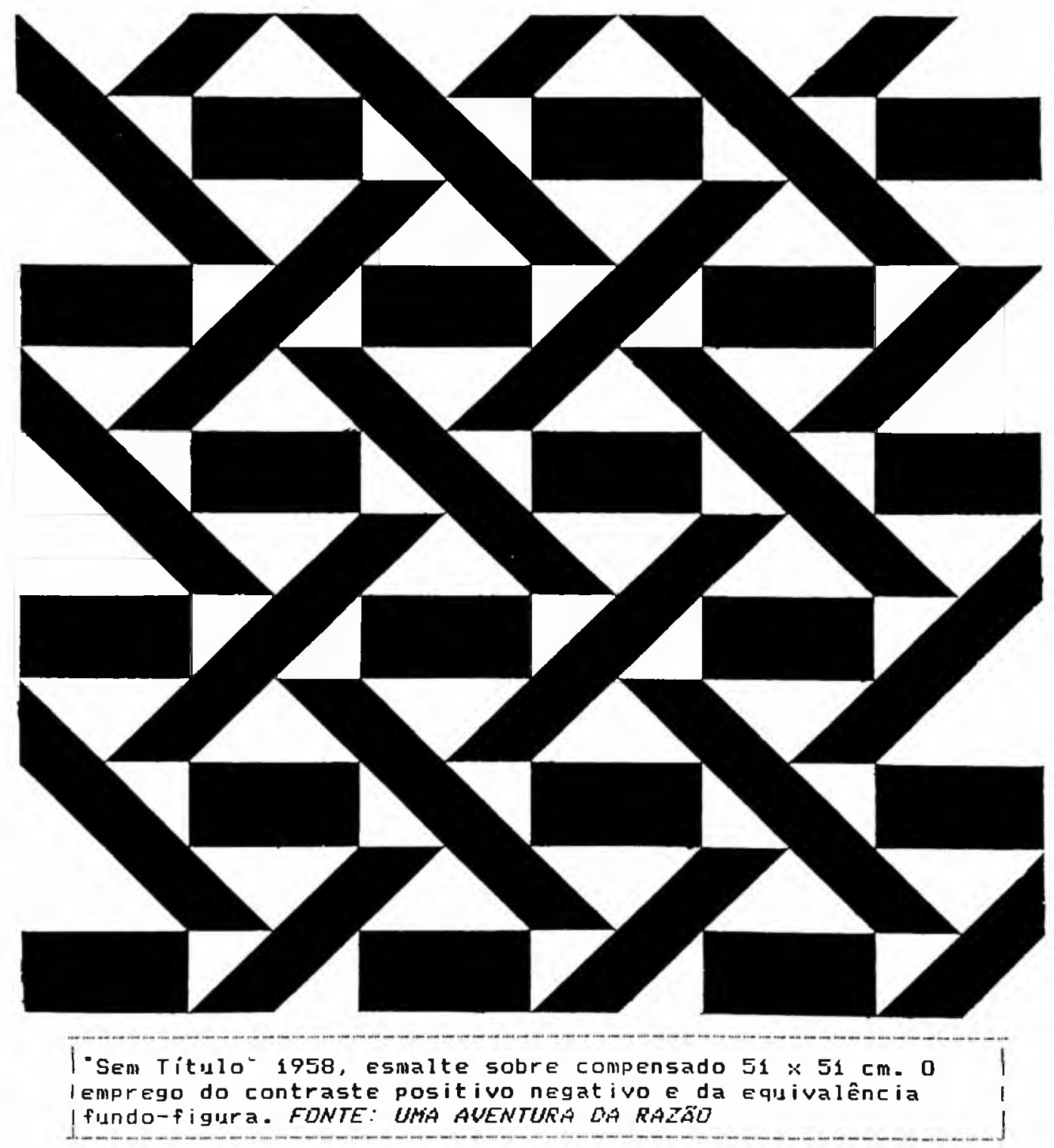


O paisagismo foi uma das formas de arte que permitiu a Cordeiro atingir ou pelo menos chegar mais próximo de seus objetivos. A solução de um jardim pressupõe também uma série de adequações funcionais e técnicas, mas permite maiores liberdades formais e cromáticas. Ou seja, seria um campo riquíssimo que Cordeiro saberia aproveitar. Somou ao paisagismo típico, diversos gêneros artísticos, como por exemplo os murais.

Cordeiro aborda a paisagem visando uma coerência ideológica com a vida moderna e o urbano moderno, bem como a toda sua produção artística. Elaborou toda uma conceituação ampla, abrangendo desde as questões puramente formais, a nível do jardim, questões do meio ambiente contrapostas à cultura e à paisagem urbana.

Pode-se destacar então os seguintes pressupostos:

"A paisagem natural não pode ser considerada como estado florestal primitivo a ser meramente conservado; ao contrário, deve ser considerada dinamicamente, como riqueza a ser usufruída pelo homem, que the dará o contexto e o uso mais adequado. Desta forma, toda a paisagem, mesmo quando composta apenas por topografia, vegetação, clima e drenagem, será cultural a partir do momento em que o homem tenciona usufruí-la. É tarefa do paisagista procurar manter, na dinâmica das interações, um equilibrio nessa paisagem; esta busca de equilíbrio acarreta soluções diversas; desde a conservação de espécies até a criação de florestas artificiais." 6

A arte, englobando o paisagismo, teria um papel fundamental como condicionante do tempo livre. O chamado "tempo livre" tem fundamental importância nos conceitos de Cordeiro, sendo definido como o tempo em que as atividades diretamente produtoras cessam. Este tempo livre seria o momento propício para a qualificação do corpo e do espírito. Um tempo para a produção em um sentido diverso do econômico-industrial.

A arte aplicada como paisagismo, paisagem urbana e recreação, teria como meta a promoção desta qualificação. Os logradouros ou sistemas para o usufruto do tempo livre desenvolveriam as potencialidades e enriqueceriam o indivíduo. Este conceito é antagônico e a ditadura da "indústria da diversão" e seus "sistemas", moldando o tempo livre pelo consumo e pelo lucro, com atividades quase sempre reduzidas a "passatempos"7

Podemos observar que o paisagismo de Cordeiro provém não de regras ou 
intuições, mas de conceitos fortemente científicos. Os jardins foram construídos sobre estes conceitos. A construção racional chegaria a atingir aspectos radicais.

A transposição das artes plásticas para o paisagismo foram evidentes no decorrer de toda a sua produção, mas. ocorrendo de maneiras diferentes nos diversos momentos por que passou a sua obra. Os trabalhos de sua primeira fase exploram uma utilização do terreno como um campo gráfico. O terreno é tratado como uma pintura ou colagem com o emprego dos materiais comuns como plantas, pisos e etc., o caráter "bidimensional" se torna marcante, entendendo-se o bidimensional não como desqualificação: mas como uma forma de tratamento feito basicamente no desenho e na cor e não tanto na volumetria.
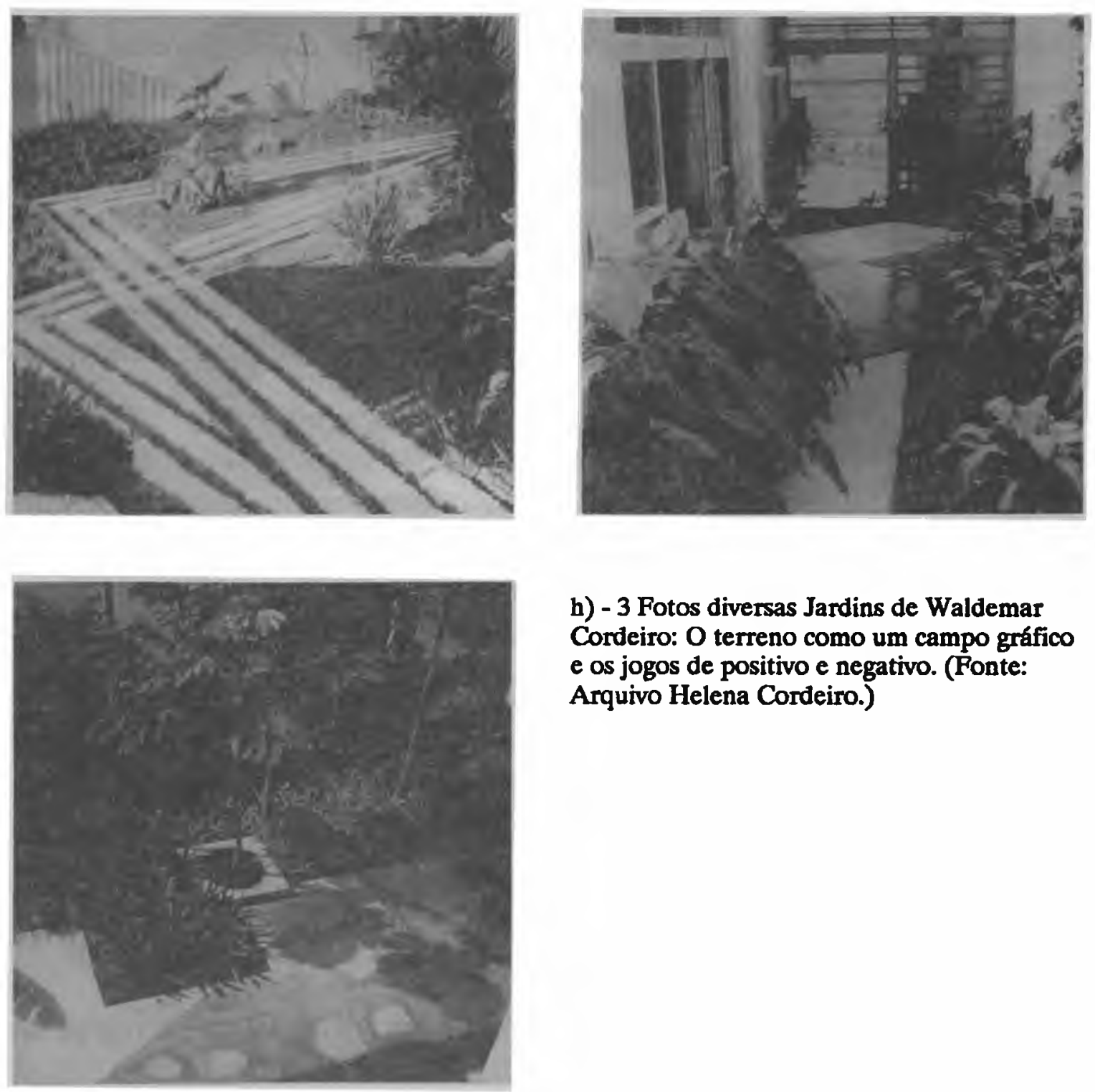

h) - 3 Fotos diversas Jardins de Waldemar Cordeiro: $O$ terreno como um campo gráfico e os jogos de positivo e negativo. (Fonte: Arquivo Helena Cordeiro.) 
Posteriormente, com as incursões em estudos e projetos mais ligados à paisagem em macroescala (parques, etc.), os jardins residenciais são tratados com novas abordagens. Nesta nova fase, a volumetria assume maior importância nos planos verticais, as linhas retas e brancas da arquitetura moderna são contrapostos à vegetação, com interessantes jogos de texturas e cores.
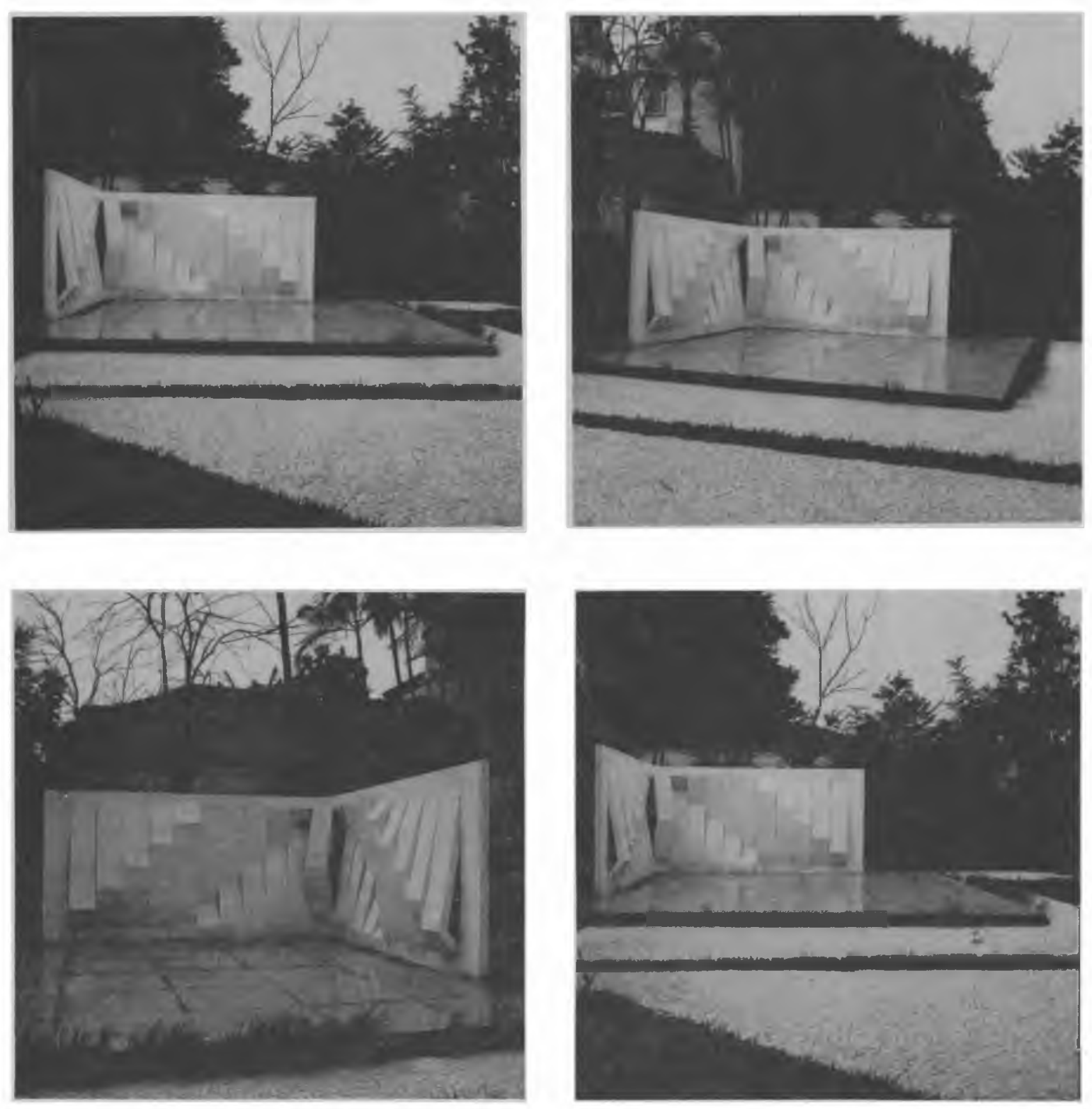

i) - Mural R Honduras Mural em Jardim Residencial: uma das possibilidades para a arte participante e integrada à arquitetura. (Fonte: Uma Aventura da Razāo.) 


\section{JARDINS DE WALDEMAR CORDEIRO:}

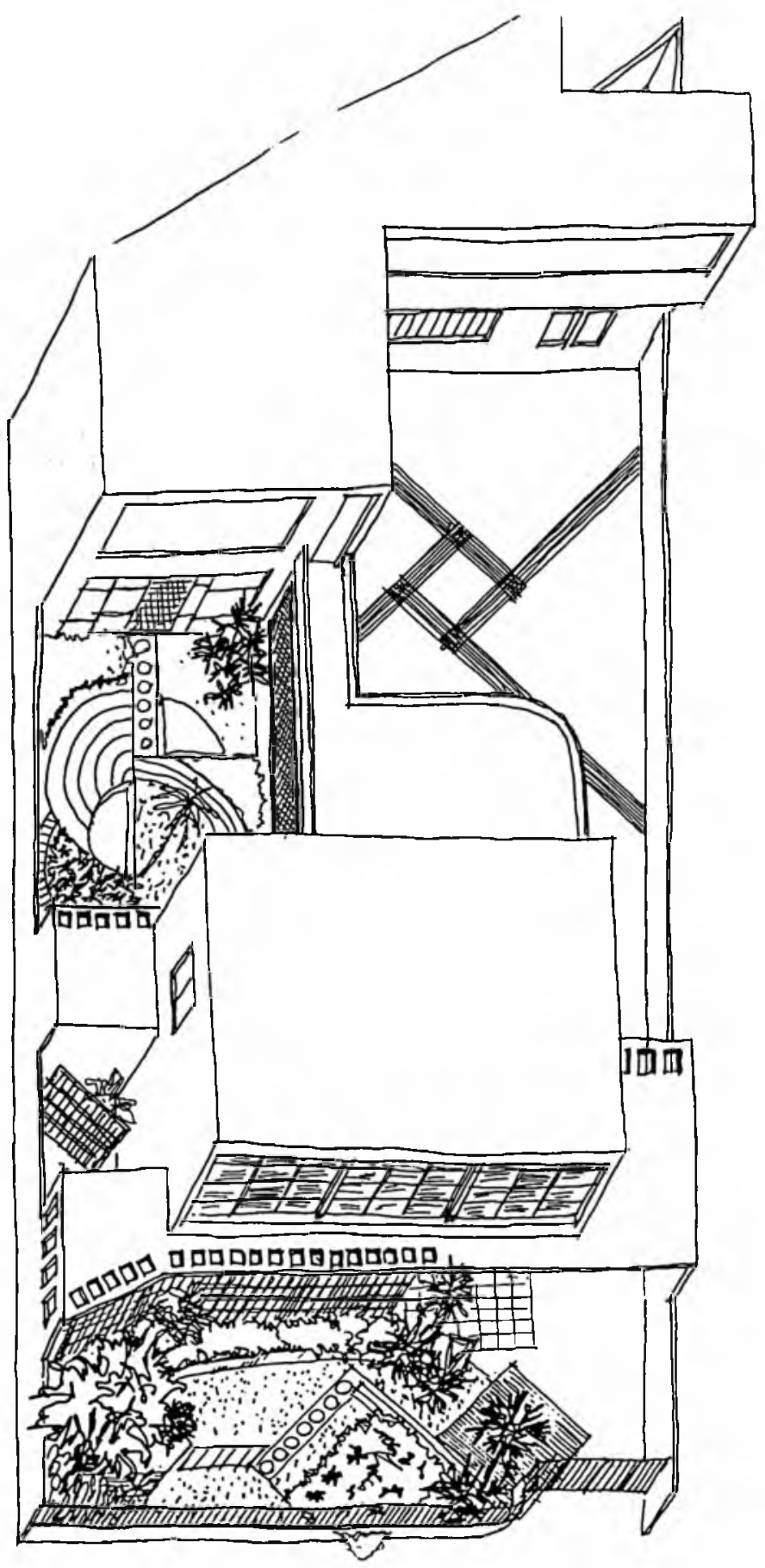

j) - Axonométrica da

Residência Keutenedjan.

Residência Ubirajara

Keutenedjan.

Rua Áustria, 95 - Jardim

Europa

- Projeto: Lauro da Costa Lima

- arquiteto

Paisagismo: Waldemar

Cordeiro - 1955 (desenho:

Marcos Castilha - fotos: arquivo Helena Cordeiro).

Este é um projeto marcadamente pertencente a primeira fase do trabalho de Waldemar Cordeiro. Pode-se observar nitidamente as transposições do pintor ao paisagista. 
A qualidade do espaço, que é tridimensional, é configurada em grande parte por elementos "bidimensionais". Cordeiro dispõe pisos e plantas baixas em curvas e deslocamentos.geométricos, muito semelhantes às suas experiências com a pintura.

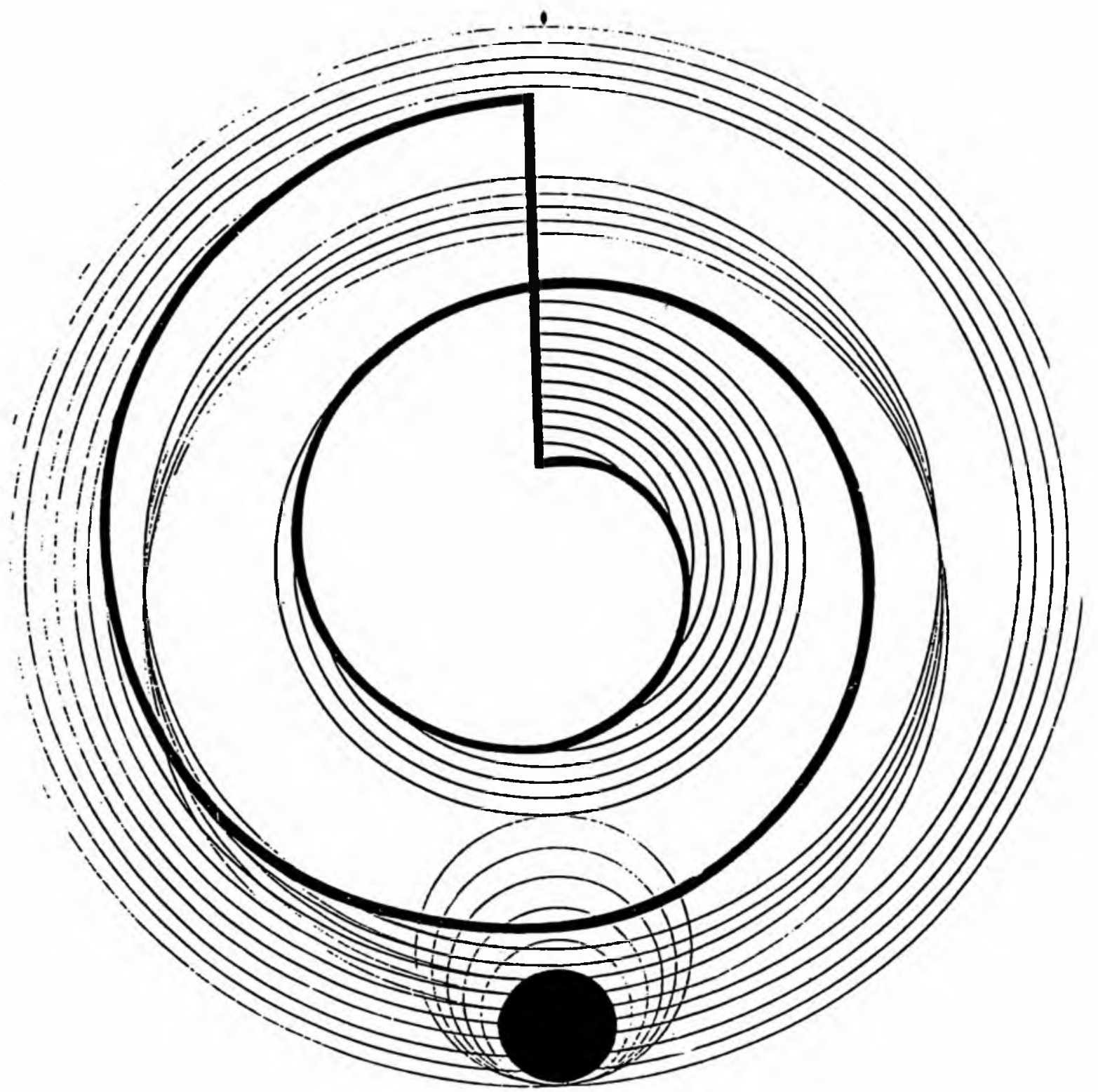

"Desenvolvimento ótico da espiral de Arquimedes", 1952. Esmalte sobre compensado 71 x 60,5. Reparem na solução gráfica muito semelhante ao jardim interno da residência Keutenedjan. (Fonte: Uma Aventura da Razão.) 

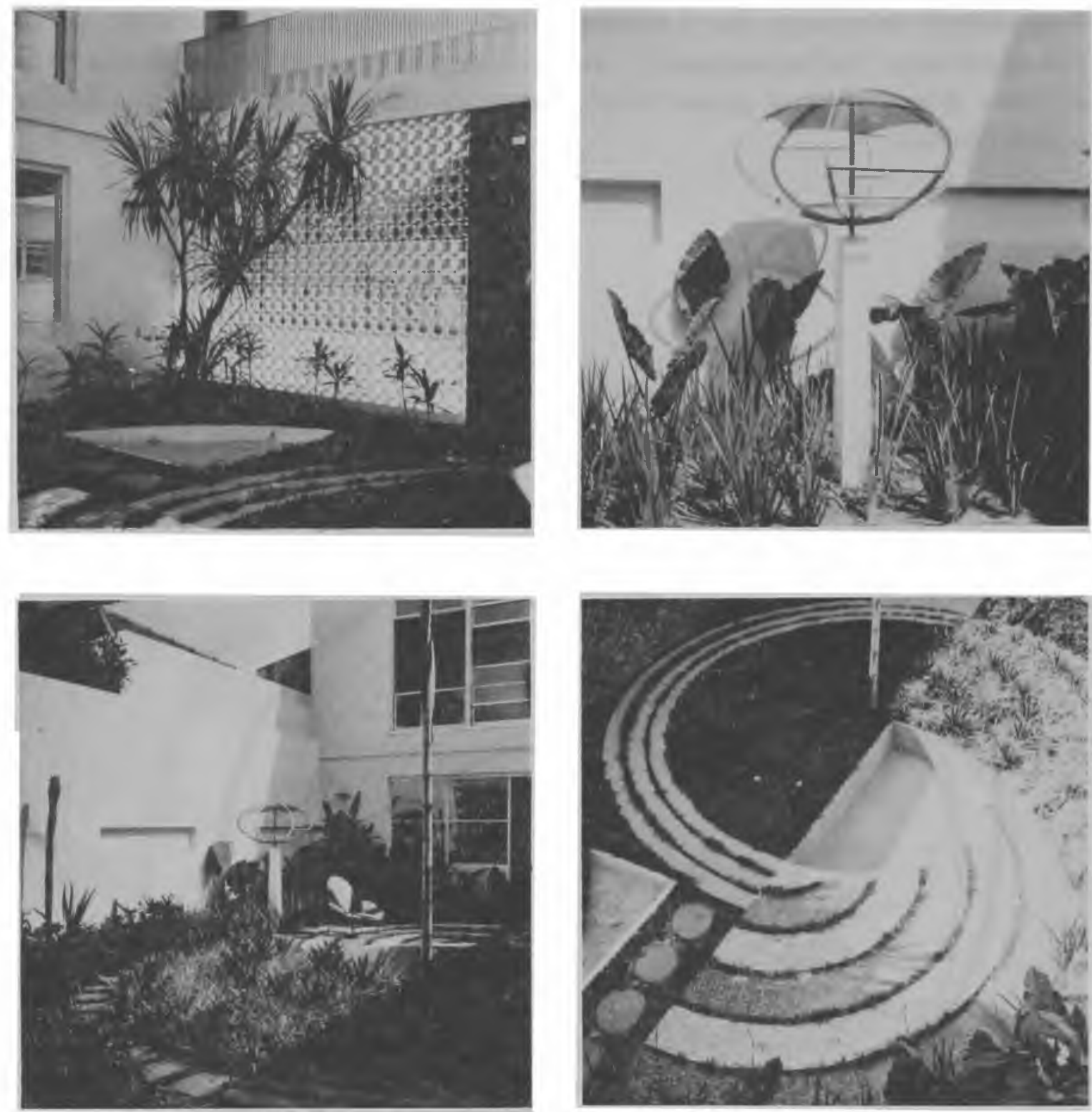

1) Fotos do jardim anterior.

\section{Edifício João Ramalho.}

- Rua Ministro Godoy, 360 - Perdizes

- Projeto: Plinio Croce, Roberto Aflalo, Salvador Candia

- Paisagismo: Waldemar Cordeiro - 1963 (desenhos e fotos: Marcos Castilha). 


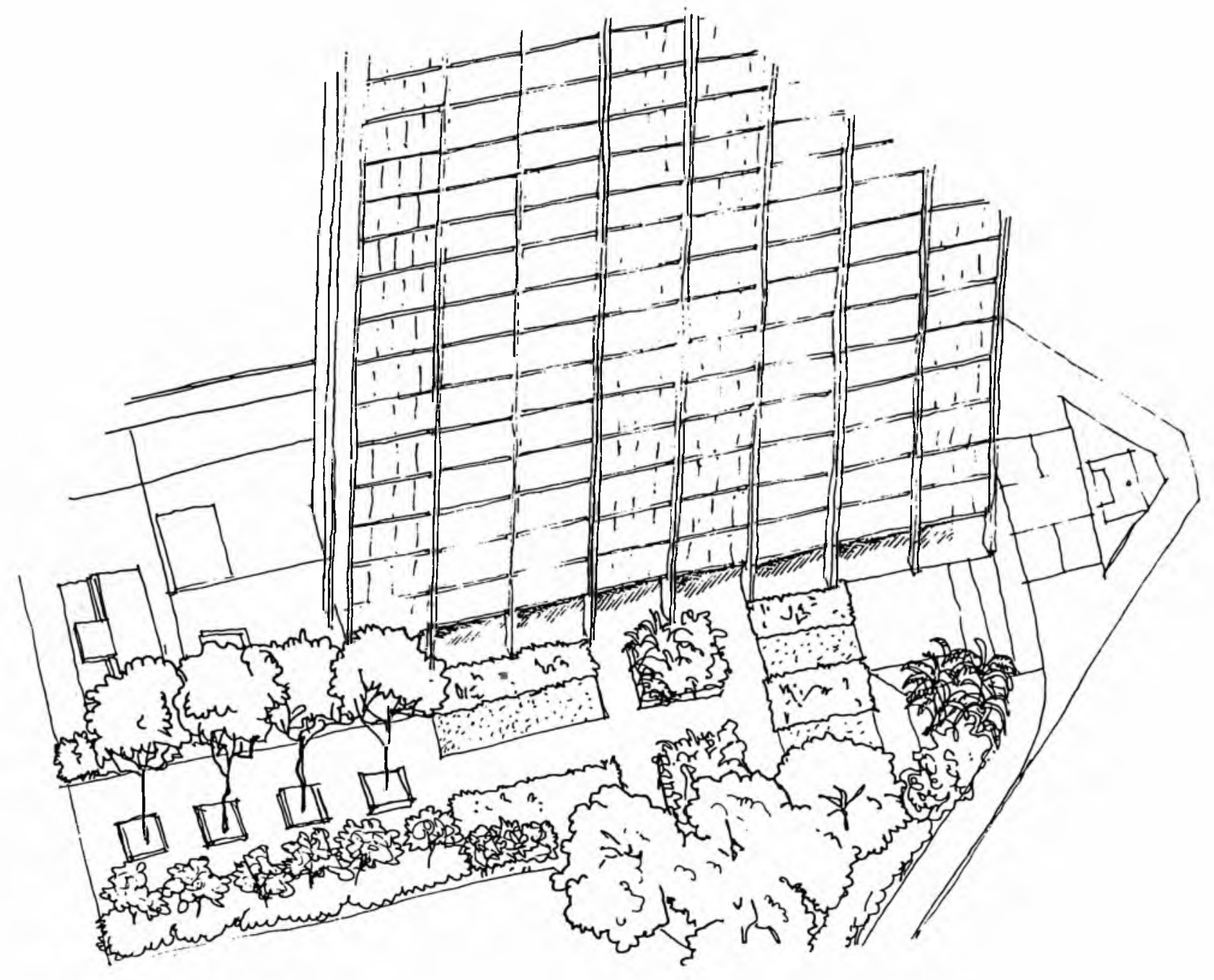

m) - Axonométrica do Jardim.

É um belo exemplo da evolução do trabalho de Waldemar Cordeiro, posterior às construções gráficas do gênero do Jardim da Residência Keutenedjan, embora permaneçam os canteiros e manchas vegetais de limites ortogonais, o jardim é fundamentalmente estruturado pelos contrastes volumétricos e de texturas.

Ocorrem jogos cromáticos entre a grama comum (verde clara) e a grama japonesa (escura). São jogos não tão drásticos quanto o positivo-negativo de projetos anteriores. Adentrando o espaço, surgem os momentos de estar, com canteiros de vegetação sortida.

Estes enquadram um eixo de aspecto ameno, dado pela sombra leve de quatro Sibipinunas.

Volumétrico, no térreo, o jardim progressivamente assume um caráter de campo gráfico quando da sua observação dos pavimentos superiores. 


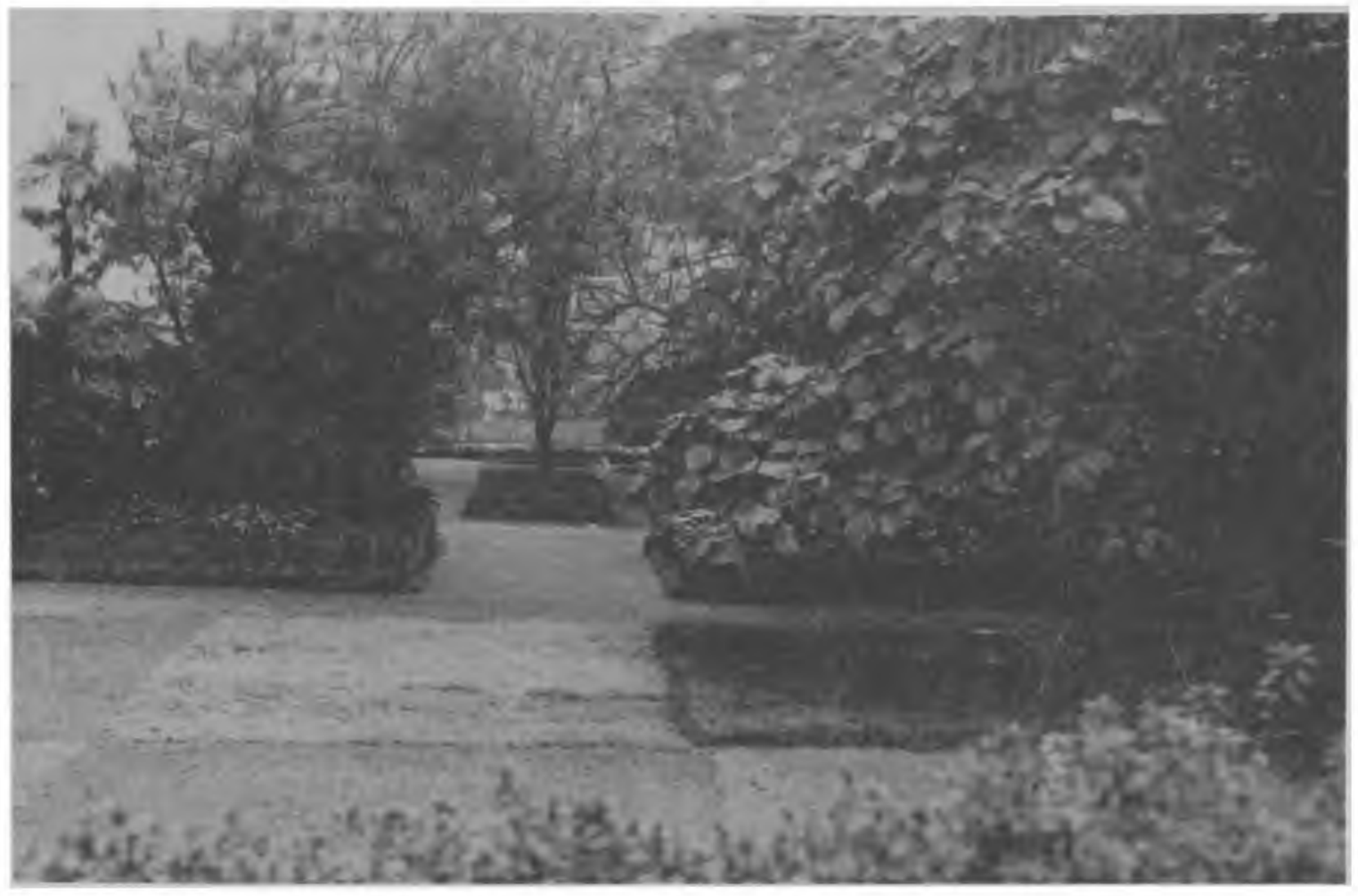

n) Fotos do Jardim João Ramalho.

Edifício King George V.

- Rua Caconde, 499 -

Cerqueira César

- Paisagismo: Waldemar

Cordeiro - 1964

(desenho: Marcos

Castilha).

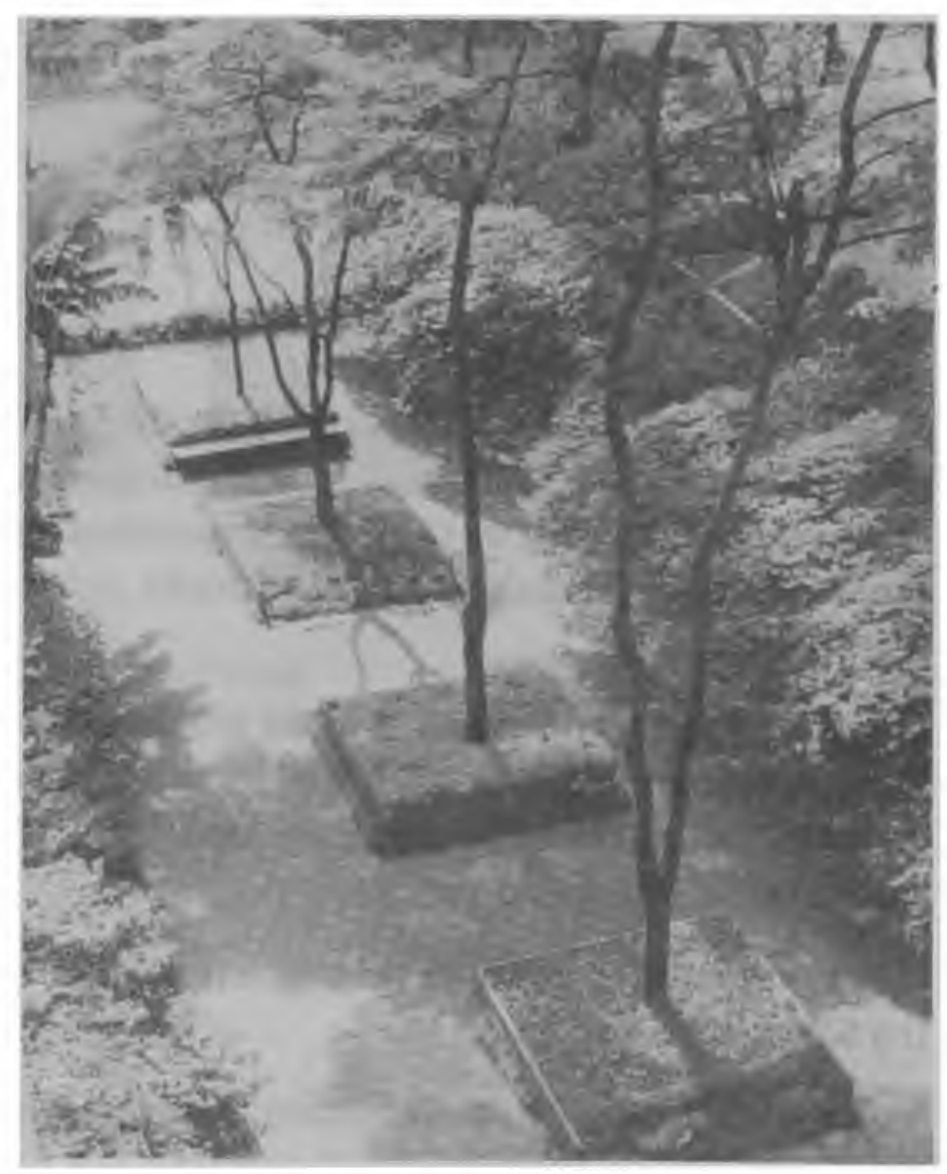




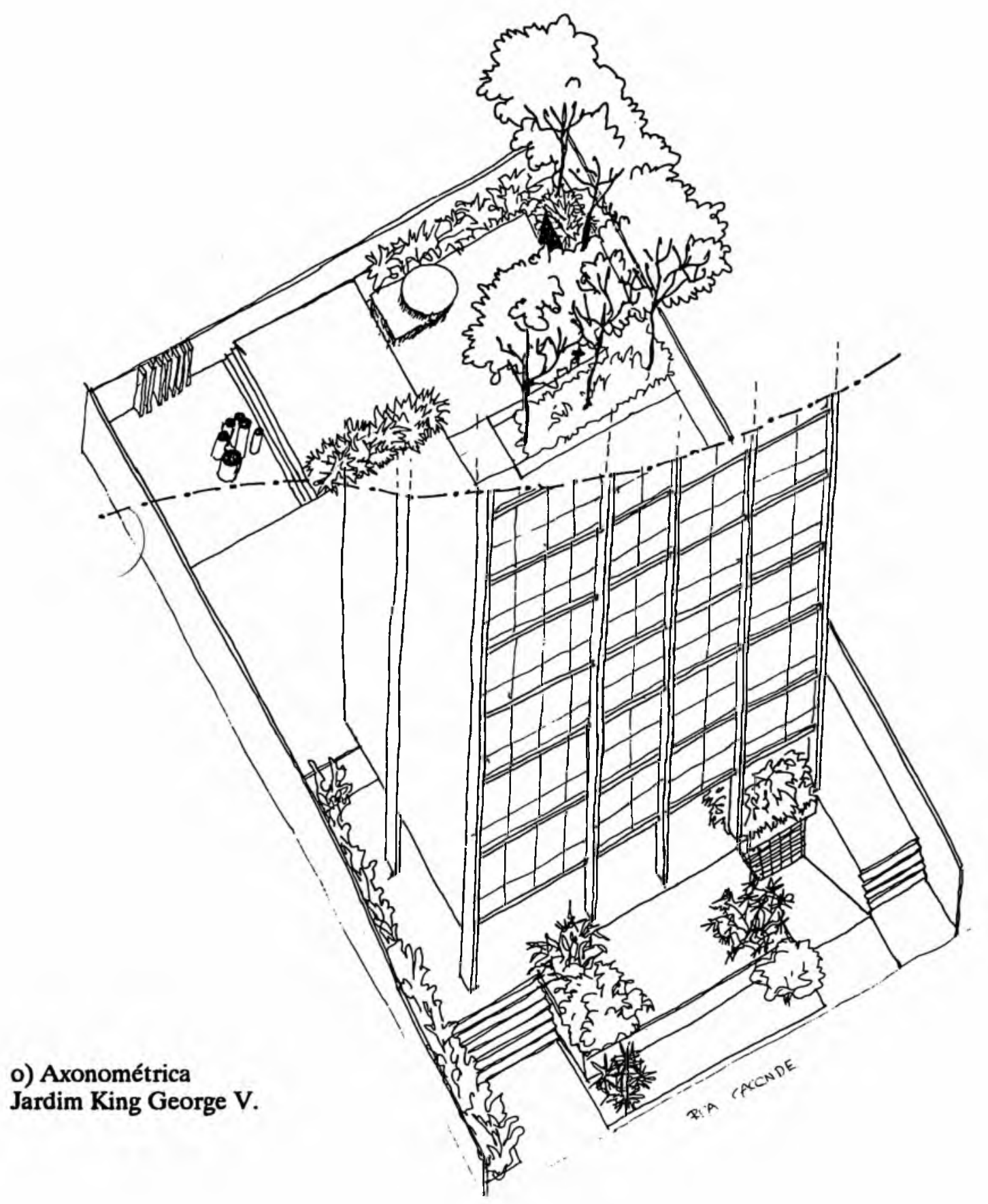

O jardim dos fundos é particularmente interessante neste projeto. Cordeiro deu uma solução revitalizando os tradicionais pátios de recreio e playground tão comuns aos fundos dos prédios de apartamentos. Aplicou seus conceitos sobre o tempo livre e estruturação deste, criando uma área de recreio à semelhança da experiência com o Clube Espéria: os brinquedos tradicionais foram substituídos por elementos que visam estimular o potencial criativo de cada criança, a exemplo do feixe de cilindros ou do quadro negro. A riqueza do ambiente se faz também pelo fato da perfeita coerência dos brinquedos com o espaço geral: a vegetação os canteiros e a grande caixa de areia. 


\section{NOTAS}

(1) Até 1937, os esforços do movimento modernista para romper aquelas limitações tiveram resultados apenas superficiais: Um tratamento arquitetônico externo de inspiração cubista, distribuído com equilíbrio pelas quatro elevações, ocultava, muitas vezes, uma estrutura de paredes de tijolos e uma disposição geral tradicional". REIS FILHO, Nestor Goulart. Quadro da Arquitetura no Brasil. São Paulo, Perspectiva. $6^{a}$ Edição, 1987, p. 76.

(2) "Em alguns projetos foi tentada mesmo a ligação da sala com o local de serviço, com a conseqüente valorização social e arquitetônica daquela peça que havia sido a mais rigorosamente desprestigiada pela organização tradicional: a cozinha.' REIS FILHO, Nestor Goulart, op. cit.p. 93.

(3) Depoimentos de professores da FAUUSP.

(4) Biografia sintética extraída de: BELUZZO, Ana Maria. Waldemar Cordeiro, uma aventura da razāo. Catálogo da exposição sobre o autor - MAC, São Paulo, 1986, p. 15-35.

(5) CORDEIRO, Helena. Revista VEJA, 6 agosto de 1986, p. 139.

(6) WILHEIM, Jorge. Proposta de Conclusões do Seminário. (Texto de conclusões sobre a paisagem feito pela Comissão do Seminário, da qual Cordeiro participava.) São Paulo, Arquivo Helena Cordeiro.

(7) CORDEIRO, Waldemar. O Tempo Livre. op.cit. 4. 